\title{
Photoredox-Catalyzed Hydrocarboxylation of Styrenes in Continuous Flow
}

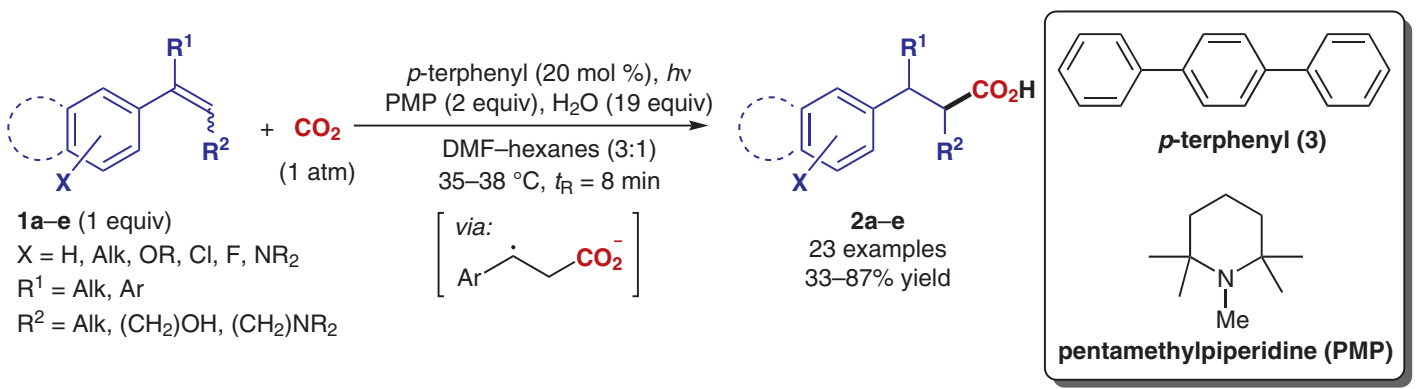

Selected examples:

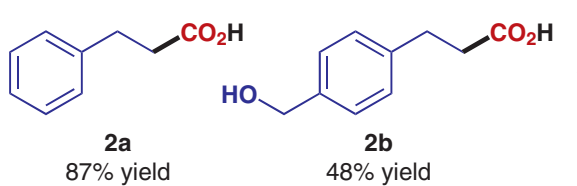

$2 a$
$87 \%$ yield

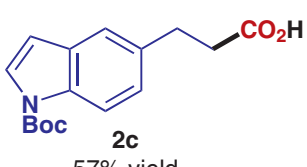

$57 \%$ yield<smiles>CC(C)C(CC(=O)O)c1ccccc1</smiles>

2d

$61 \%$ yield

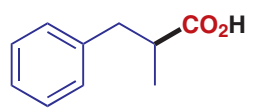

$2 \mathrm{e}$

from trans: $42 \%$ yield from cis: $66 \%$ yield

Proposed mechanism:

Continuous flow set-up:
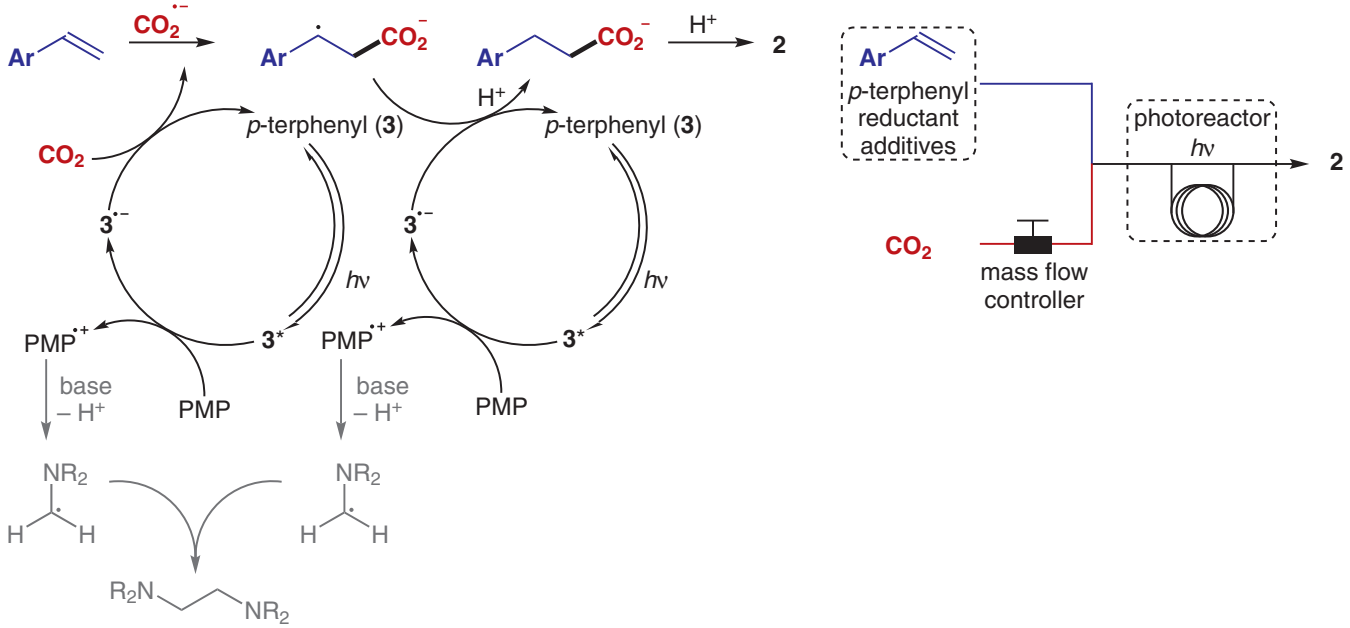

Significance: Jamison and co-workers present a photoredox-catalyzed hydrocarboxylation of styrenes using $\mathrm{CO}_{2}$ and pentamethylpiperidine (PMP). The reactions are performed in flow ( $\left.t_{R}=8 \mathrm{~min}\right)$ to provide the anti-Markovnikov adducts in moderate to good yields with high degrees of chemo- and regioselectivity. Functional group tolerance and preliminary mechanistic investigations are disclosed.

SYNFACTS Contributors: Benjamin List, Jennifer L. Kennemur Synfacts 2017, 13(12), $1311 \quad$ Published online: 17.11.2017 Dol: 10.1055/s-0036-1591648; Reg-No.: B10017SF
Comment: This method offers a complementary approach to metal-catalyzed hydrocarboxylation reactions of styrenes, which often afford the corresponding Markovnikov adducts. Metal catalysis has recently been used to affect hydrocarboxylation reactions of simple olefins (M. Gaydou,

T. Moragas, F. Juliá-Hernández, R. Martin J. Am. Chem. Soc. 2017, 139, 12161). A similar substrate expansion to simple alkyl olefins would bolster the synthetic capacity of this methodology.

\section{Key words}

photoredox catalysis

continuous flow

hydrocarboxylation

styrenes

phenylpropanoic acids

carbon dioxide

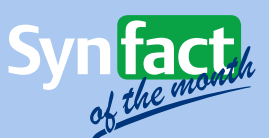

